\title{
Non-ejection systolic clicks and mitral systolic murmurs in Black schoolchildren of Soweto, Johannesburg ${ }^{1}$
}

\author{
M. J. McLaren, D. M. Hawkins, 2 A. S. Lachman, J. B. Lakier, W. A. Pocock, \\ and J. B. Barlow
}

From the Cardiovascular Research Unit, Department of Medicine, University of the Witwatersrand; and the Cardiac Clinic, General Hospital, fohannesburg, South Africa

A survey was conducted on 12050 Black schoolchildren, aged 2 to 18 years, in the South Western Townships of Fohannesburg (Sozveto), and the prevalence of non-ejection systolic clicks and late systolic murmurs was determined. One or both of these auscultatory findings were detected in 168 children, yielding a prevalence rate of 13.99 per 1000 in the school population. A female preponderance of 1.9:1 was present and there was a strong linear increase in prevalence with age, with a peak rate of 29.41 per 1000 in 17-year-old children. A non-ejection click was the only abnormal auscultatory finding in 123 children (73\%) and a mitral systolic murmur in $8(5 \%)$, whereas in $37(22 \%)$ both these findings were present. Of the latter 37 children, the murmur was late systolic in $32 ;$ in 5 it was early systolic. Auscultation in different postures was important in the detection of both non-ejection clicks and mitral systolic murmurs. Experience in the detection of these auscultatory findings influenced the frequency with which they were heard. Electrocardiographic abnormalities compatible with those previously described in the billowing mitral leaflet syndrome were present in 11 of 158 children.

The aetiology of these auscultatory findings in this community remains unknown. In the same survey, a high prevalence rate of rheumatic heart disease was recorded and the epidemiology of the non-ejection clicks and these mitral systolic murmurs showed similarities to that of rheumatic heart disease. Though the specific billowing mitral leaflet syndrome almost certainly accounts for some of these auscultatory findings, a significant proportion may have early rheumatic heart disease. Further elucidation of this problem is necessary.

A non-ejection systolic click, late systolic murmur, or both, are attributed to billowing of the mitral leaflets, especially the posterior one. Since the possibility of a mitral valve origin for these auscultatory findings was revived by Reid (1961), there have been numerous publications on different aspects of this somewhat complex entity. These include clinical (Barlow et al., 1968; Jeresaty, 1973; Cobbs, 1974; Barlow and Pocock, 1975), aetiological (Pocock and Barlow, 1971; Barlow and Pocock,

\section{Received 7 November 1975.}

'Supported by South African Medical Research Council, Anglo American Corporation of South Africa Limited, and South African Breweries Institute.

sPresent address: Department of Applied Mathematics, University of the Witwatersrand, Johannesburg, South Africa.
1975), and familial (Barlow, 1965; Hancock and Cohn, 1966; Shell et al., 1969) studies as well as an analysis of angiocardiographic (Criley et al., 1966; Grossman et al., 1968), electrocardiographic (Pocock and Barlow, 1971; Jeresaty, 1973; Barlow and Pocock, 1975), echocardiographic (Popp et al., 1974), and pathological (Shappell et al., 1973; Barlow and Pocock, 1975) manifestations. Considerable further interest has been stimulated by the recognition of an association with arrhythmias (Hancock and Cohn, 1966; Pocock and Barlow, 1970; Barlow and Pocock, 1975) or conduction defects (Gulotta et al., 1974; Barlow and Pocock, 1975), and the predisposition to the development of infective endocarditis (Linhart and Taylor, 1966; Barlow et al., 1968; Lachman et al., 1975). Despite the wealth of literature, the prevalence and, there- 
fore, the significance of these features in the general population have not yet been ascertained. Only one population survey has been published and this was in Bari, Italy (Rizzon et al., 1973), where 1009 young adult women were auscultated and a non-ejection systolic click, late systolic murmur, or both were detected in 3.3 per 1000 . In previous communications from this laboratory (Barlow et al., 1968; Pocock and Barlow, 1971), these auscultatory signs were reported in 220 patients, 210 of whom were White. Subsequently, we have encountered more than 200 additional White patients, most of whom were referred to this Unit for elucidation of their abnormal auscultatory findings or electrocardiograms or because of symptoms such as chest pain, palpitation, and syncope (Barlow and Pocock, 1975). The prevalence in the general population cannot be determined from these numbers, and variations with age, ethnic group, and geographical site are also unknown.

In 1972, a cardiological survey was undertaken on schoolchildren of the South Western Townships (Soweto) for Blacks, near Johannesburg, with the primary objective of determining the prevalence of rheumatic heart disease in that population (McLaren et al., 1975). The survey also provided an opportunity for finding out the prevalence of nonejection systolic clicks with or without mitral systolic murmurs.

\section{Subjects and methods}

A total of 12050 children were randomly selected from 58 primary schools and 32 crèches in Soweto to represent a total Black school population of about 99000 . The method of sampling has been previously described (McLaren et al., 1975) and was based on a stratified technique, in which the population was divided into 3 strata according to educational level-crèche children ( 2 to 6 years old), lower primary schoolchildren (first 4 school years), and higher primary schoolchildren (fifth to eighth school years). An age range of 2 to 18 years was thus obtained and the sex distribution was equal.

The children were examined by a team of 10 doctors, 5 of whom were experienced cardiologists and the remainder had all received at least 6 months training in this Unit. Three observers were present at each session and at least one of them was a senior cardiologist. Auscultation was performed on all children in the supine and left lateral positions. A random 10 per cent of children were also examined in the erect and squatting postures, as were those in whom the cardiac findings necessitated further elucidation, such as in children with a non-ejection systolic click, late systolic murmur, or an arrhythmia. Children with normal hearts were examined by one observer only, but when an abnormal heart was suspected or detected, the child was then 'recirculated' to the other 2 observers who were unaware that the child had already been examined. Initially, the children with non-ejection clicks or late systolic murmurs were likewise 'recirculated', but this practice was soon abandoned when it became apparent that these findings were common and that their often transient nature sometimes led to their temporary disappearance when the children were later re-examined. However, the presence of either a non-ejection click or a late systolic murmur had to be confirmed by at least one of the other 2 observers. Electrocardiograms and blood pressure determinations were recorded on children with abnormal hearts and on those routinely postured.

The age, sex, home, and school areas of the children as well as family size, as assessed by the number of sibs, were documented. The educational grades of the children were also noted because, despite some correlation with age, there is a considerable age variation in each grade. Though ethnic group was recorded, this factor is of doubtful significance in this urban community in which the inhabitants represent many different Black ethnic groups but are differentiated to a large extent by language only. Other observations included a clinical and anthropometric nutritional assessment and the carrier rate of Lancefield's Group A betahaemolytic streptococcus in the throat. Statistical analysis was based on two techniques, a $\chi^{2}$ test for nominal data and an unpaired Student's $t$ test for all interval data.

\section{Results}

\section{Prevalence}

A non-ejection click, a late systolic murmur, or both, were detected in 168 children, yielding an overall prevalence rate in the sample school population of 13.99 per 1000 . The optimally weighted estimate of the prevalence in the total school population (Cochran, 1963; McLaren et al., 1975) was 13.42 per 1000 with a 95 per cent confidence interval of $\pm 2 \cdot 1$. Three children were considered (McLaren et al., 1975) to have established rheumatic heart disease with associated nonejection clicks and are not included in the 168. The prevalence rate in crèche children was 5.26 per 1000 while in the lower primary and higher primary schoolchildren it was 11.84 and 17.76 per 1000 , respectively.

Of the 168 children with these auscultatory 


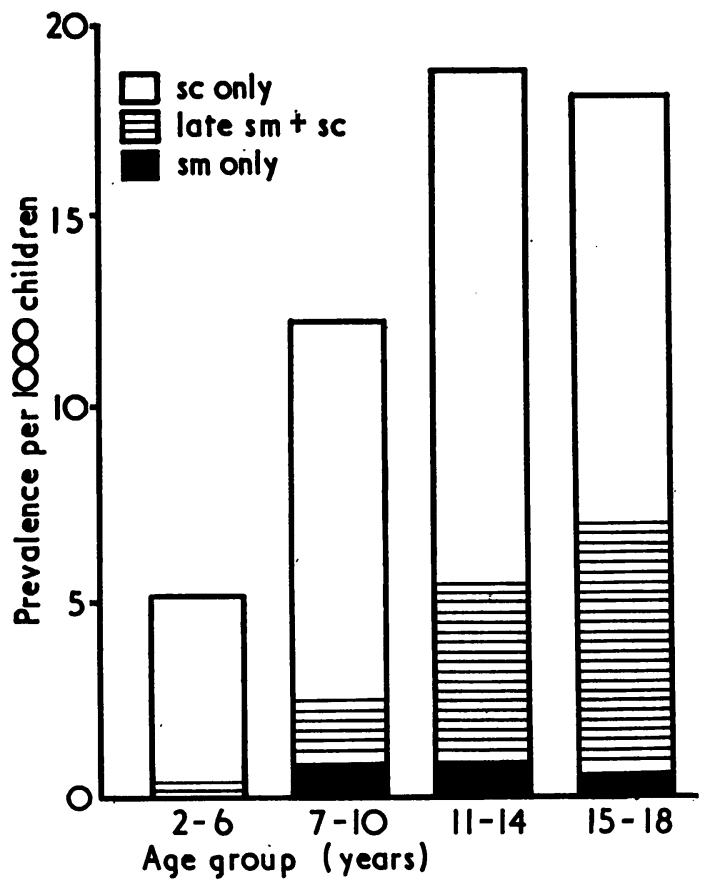

FIG. 1 Varying prevalence of non-ejection systolic clicks (SC), late systolic murmurs (late SM), or both (late $S M+S C$ ) with age. There is a linear association $(P<0.001)$.

findings, 32 had been routinely postured and the prevalence rate for this group (1174 children) was 27.3 per 1000 . If the children examined by the less experienced observers are excluded from the sample, then the overall prevalence is increased to 19.2 per 1000 .

\section{Epidemiological factors}

The sex ratio showed a female preponderance of 1.9 :1. A strong linear association $(P<0.001 ;$ Fig. 1$)$ between age and prevalence was present (a test for non-linearity was not significant, $\chi^{2}=16.41$, $P>0.05)$. The youngest age recorded was 3 years ( 3 children with isolated non-ejection clicks) and the maximal prevalence rate of 29.41 per 1000 occurred in children aged 17 years. If the individual school grades are considered (Fig. 2), the peak prevalence rate was recorded in the seventh and eighth school grades $(P<0.01)$.

There was no significant correlation between prevalence and family size, ethnic group, home area, or school area $(P>0.05)$.

Throat cultures were carried out in all but 6 of the 168 children. The carrier rate of Lancefield's Group A beta-haemolytic streptococcus was 61.7 per 1000 but this is not significantly greater $(P>0.05)$ than the carrier rate in the children with normal hearts (52 per 1000).

The nutritional status of children with nonejection clicks with or without mitral systolic murmurs was assessed clinically as average in 82 per cent, undernourished in 14 per cent, and unusually well-nourished or obese in 4 per cent. In children with normal hearts, these figures were 86,7 , and 7 per cent respectively.

\section{Auscultatory features}

A non-ejection click only was heard in 123 children $(73 \%)$, an isolated mitral systolic murmur in $8(5 \%)$, and both these auscultatory findings in $37(22 \%)$.

\section{Non-ejection systolic clicks}

A non-ejection systolic click was the commonest abnormal auscultatory finding and was detected in 160 children or 13.3 per 1000 of the school population. It was loudest at the left parasternal border in 74 children $(46 \%)$, over the cardiac apex in 60 $(38 \%)$, and at both these sites in $26(16 \%)$. In 86 children $(54 \%)$ the click was present intermittently.

The click was audible in all postures in 57 per cent of children. In 84 per cent it was heard in more than one posture and if present in only one posture this was most frequently the standing position $(11 \%)$. In the supine position, 22 per cent of clicks were not heard and would thus have been missed if auscultation in the other postures had been omitted. The presence of extrasystoles in 2 children led to their being postured and a click was then detected on standing. In another 2 the click became audible on re-examination in the supine position after posturing.

\section{Mitral systolic murmurs}

The diagnostic criteria for a 'mitral systolic murmur' in this group of children were either a late systolic murmur with or without a non-ejection click, or an apical early systolic murmur (Barlow and Pocock, 1975) provided this was associated with a nonejection click. A mitral systolic murmur was present in 45 children $(27 \%)$, yielding a prevalence rate for the school population of 4 per 1000. In 40 children the murmur was classified as late systolic and this was associated with a non-ejection click in all but 8 . The remaining 5 children had an early systolic murmur and non-ejection click.

In the supine position 32 of the 45 murmurs were present and, with the exception of 2 murmurs of grade $3 / 6$ intensity, all were grade 1 to 2 . In one child the intensity of the murmur changed from grade 3 to grade 4 on standing and squatting.

The effect of posture on the length of the murmur 


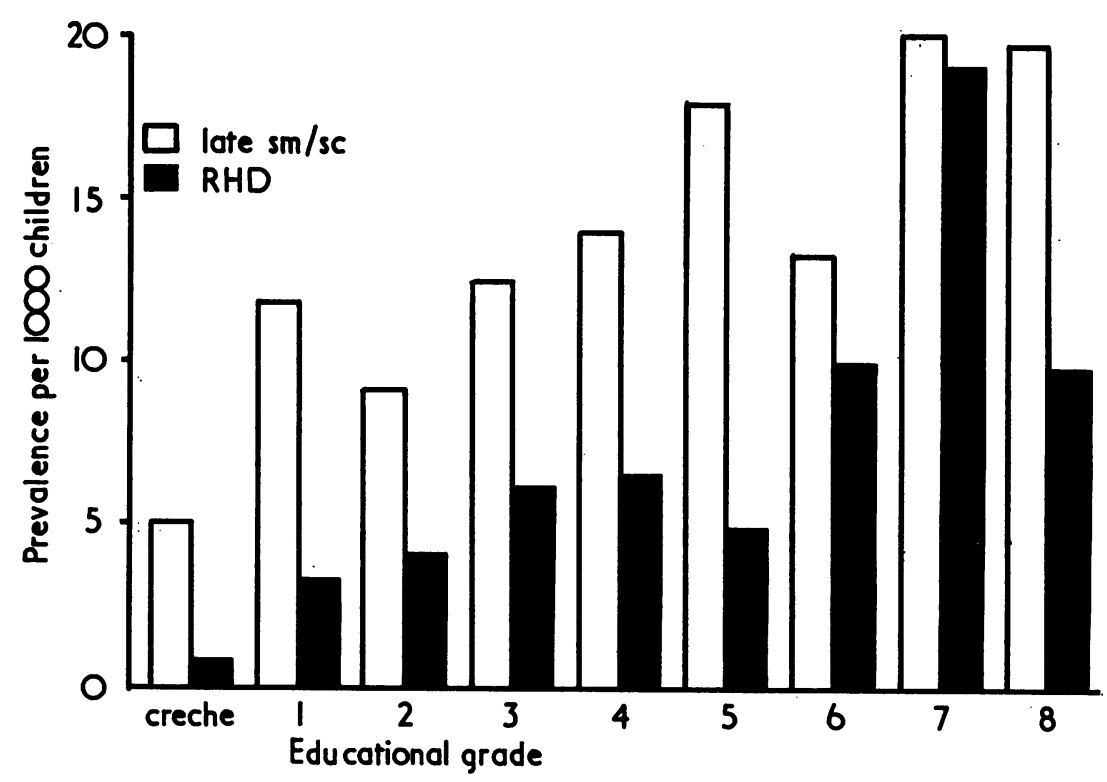

FIG. 2 Association of prevalence of late systolic murmurs and/or non-ejection systolic clicks (late $S M / S C)$, and rheumatic heart disease (RHD) with educational grade.

was stated in 36 children only. In 4 children the murmur became pansystolic on standing. In 2 of them the murmur was late but long in the supine position and no non-ejection click was present, while in the other 2 the murmur was early systolic in the supine position and was associated with a non-ejection click. Of the early systolic murmurs detected in 3 further children, one was present in the supine position and became late systolic on standing and squatting, one was present in the supine and squatting positions and did not become late systolic, and one was audible in the standing position only. The mitral systolic murmur was absent in the supine position in 13 children. In 2 of them the murmur became audible in the left lateral position, whereas in the remainder it became apparent only when the child was examined in the standing position either routinely or because of the detection of a non-ejection click in the supine position.

\section{Physiological murmurs and third heart sounds}

In addition to the above auscultatory findings, a vibratory systolic murmur or Still's murmur (Still, 1915) was present in $62(37 \%)$ of the 168 children, which was less frequent than in the general school population. A physiological third heart sound was heard in $153(91 \%)$, whereas the overall prevalence in the school population was 97 per cent.

\section{Blood pressure and electrocardiograms}

The systolic and diastolic blood pressures did not differ from those of the control population.

Of the 158 children who had a technically satisfactory electrocardiogram, $11(7 \%)$ had abnormalities compatible with those previously described in the billowing mitral leaflet syndrome (Hancock and Cohn, 1966; Pocock and Barlow, 1971; Jeresaty, 1973; Barlow and Pocock, 1975). Flattening or inversion of the $T$ waves in the inferior leads (II, III, and aVF) and mid or lateral praecordial leads was present in 8 children, whereas 2 had inferior changes only and in the remaining child, a 14-year-old girl, inverted $T$ waves were confined to the chest leads V1 to V5. A late systolic murmur was the abnormal auscultatory finding in 3 of these children and a non-ejection click in 5, while in 3 both findings were present.

\section{Discussion}

The Soweto survey has revealed that non-ejection clicks and late systolic murmurs are common abnormal auscultatory findings in Black schoolchildren. The prevalence was highest in adolescent children of 11 to 18 years of age, but in all agegroups it was greater than that reported in young adult women of the Bari survey (Rizzon et al., 1973). Certain other characteristics of these findings 
have been confirmed. There was a female preponderance and this has been reported (Barlow et al., 1968; Jeresaty, 1973) in the billowing mitral leaflet syndrome. The importance of posture in the detection of non-ejection clicks and these mitral systolic murmurs (Fontana et al., 1970; Cobbs, 1974; Lachman et al., 1975) is further emphasized and auscultation in the standing position proved the most contributory. An early systolic murmur as detected in 5 children in this survey has previously been described (Cobbs, 1974; Barlow and Pocock, 1975). That awareness of these auscultatory findings and experience in their detection influence the frequency with which they are heard (Lachman et al., 1975) was confirmed by the higher prevalence rate obtained by the more experienced observers.

Before the significance of the high prevalence of these auscultatory findings in this community can be assessed, it is necessary to examine some of the aetiological factors which may affect the complex mitral valve mechanism (Barlow and Pocock, 1975). At the outset, it is possible to exclude occlusive coronary artery disease because of its extreme rarity in this population group even in adults (Seftel, Kew, and Bersohn, 1970). There was no clinical evidence of hypertrophic obstructive cardiomyopathy, which is also extremely rare in South African Blacks (Tucker et al., 1975), nor was there associated congenital heart disease, previous mitral valvotomy, or trauma. Congestive cardiomyopathy is prevalent in Southern Africa in Blacks of all ages (Schwartz, Schamroth, and Seftel, 1958; McLaren, 1969) but is almost always characterized by cardiac enlargement and congestive heart failure, neither of which was detected in the Soweto children. Subvalvar left ventricular aneurysms are a recognized entity in this community (Kanarek et al., 1973) and, therefore, must be considered as a possible aetiological factor, but there was no other clinical or electrocardiographic evidence to suggest their presence. Though there were no overt features of Marfan's syndrome, it is possible that a similar pathological process affecting the mitral valve mechanism accounted for some of the nonejection clicks or mitral systolic murmurs in these children. Such patients with no skeletal manifestations of Marfan's syndrome have been previously recognized and the condition has been referred to as the 'floppy valve syndrome' (Read, Thal, and Wendt, 1965). When this presents with significant mitral regurgitation at a young age or with associated aortic, pulmonary, or organic tricuspid regurgitation the 'floppy valve syndrome' is a likely diagnosis. However, in the early stages, a late systolic murmur or non-ejection click may be the only signs and it may be impossible (Barlow and Pocock, 1975) to differentiate this forme fruste of Marfan's syndrome from the 'billowing mitral leaflet syndrome'.

The two probable underlying aetiological factors for these auscultatory findings in Soweto children are either the specific entity of the 'billowing mitral leaflet syndrome' or rheumatic heart disease. In this same survey, an overall prevalence rate for rheumatic heart disease of 6.9 per 1000 was obtained in children aged 2 to 18 years, and a peak rate of 19.2 per 1000 in children of the seventh school grade was recorded (McLaren et al., 1975). It is obviously important in the management of children with late systolic murmurs or non-ejection clicks to determine whether rheumatic heart disease is a factor in their pathogenesis. Though it was disputed by some workers (Tavel, Campbell, and Zimmer, 1965; Criley et al., 1966; Jeresaty, 1973), there is now little doubt that rheumatic heart disease can give rise to these auscultatory findings (Leon et al., 1966; Willems et al., 1969; Epstein and Coulshed, 1973; Kalbian, 1973; Allen, Harris, and Leatham, 1974). Cobbs (1974) acknowledges that a late systolic murmur is not uncommon in rheumatic mitral regurgitation, but regards accompanying non-ejection clicks as being rare. However, in the Soweto survey, non-ejection clicks were audible in 3 children with established rheumatic heart disease, all of whom had an apical pansystolic murmur, and in 2 mitral stenosis was associated. Prolapse of the mitral leaflets has been shown by echocardiography in patients with rheumatic mitral regurgitation (Steinfeld et al., 1974), and regression of the prolapse has been reported in some patients with disappearance of the systolic murmur. A decreased intensity or disappearance of the pansystolic murmur of rheumatic mitral regurgitation has been seen (Wilson, 1962; Kalbian, 1973; Barlow and Pocock, 1975) after the acute carditis has subsided, provided that recurrences of rheumatic fever are prevented. During this process of regression, the pansystolic murmur may become confined to late systole before disappearing (Pocock and Barlow, 1971; Cobbs, 1974). The mechanism for such reversible mitral regurgitation was assumed to be a consequence of healing of the inflammatory process involving the leaflets. Recently this concept has been challenged (Kalbian, 1973; Cobbs, 1974) and an alternative explanation that rheumatic coronary vasculitis results in temporary papillary muscle dysfunction has been postulated (Kalbian, 1973). In South Africa, pronounced dilatation of the mitral annulus is frequently seen in Black children with mitral regurgitation caused by rheumatic heart disease (Chesler et al., 1966; du Plessis and Chesler, 1969), and the leaflets themselves may often be spared or only midly involved. Such annular dilata- 
tion may be the result of direct involvement of the annulus by the rheumatic process. In the early stages or where the process is mild, the physiological decrease in size of the annulus during ventricular systole may be partly or entirely lost and this feature could well be reversible (Barlow and Pocock, 1975). Temporary 'annular dysfunction' may thus play an important role in transient or partially reversible mitral regurgitation and explain the late systolic murmur observed in some patients. Alternatively, in those patients in whom the late systolic murmur persists, damage to the papillary muscle as a consequence of the rheumatic process may be a factor. A non-ejection click in patients with rheumatic heart disease may result from rheumatic involvement of the chordae tendineae, unequal prolapse of the mitral leaflets, or papillary muscle dysfunction.

Although the Soweto survey does not provide any conclusive evidence for a rheumatic aetiology of these auscultatory findings, it is relevant that there are also no factors that contradict this hypothesis. The epidemiology of rheumatic heart disease and these features was strikingly similar, but this may be largely non-specific and coincidental. Rheumatic heart disease was also more common in women (McLaren et al., 1975) but a female preponderance has been reported in the billowing mitral leaflet syndrome (Pocock and Barlow, 1971; Jeresaty, 1973). The prevalence of both rheumatic heart disease and these auscultatory findings showed a strong linear relation with age and though this trend suggests that there is a constant exposure of these children to processes which then often leave a permanent residual lesion, it does not necessarily indicate that the operative aetiological agent is the same in both conditions. Rheumatic heart disease was also more prevalent in the higher primary schools (Fig. 2), and it is interesting that the prevalence rate was approximately equal to that of the late systolic murmurs and non-ejection clicks in the seventh school grade. Unlike these auscultatory findings, the prevalence of rheumatic heart disease dropped in the eighth school grade to 9.9 per 1000 which made us speculate (McLaren et al., 1975) that this may be the result of a fall in attendance of older children who have more severe rheumatic heart disease or to a failure of such children to attain the higher school grade. Alternatively, the high prevalence in children of the seventh grade could be the result of a streptococcal epidemic in previous years. Undernutrition as a rough clinical assessment was more common in children with these features than in those with normal hearts, and if this is confirmed by anthropometric analysis it may indicate a higher susceptibility to the development of rheu- matic fever. However, the billowing mitral leaflet syndrome is said to occur more commonly in asthenic individuals (Bon Tempo et al., 1975). An important difference in the epidemiology of rheumatic heart disease and these auscultatory features was that the latter showed no correlation with family size and thus, by inference, with the degree of overcrowding, which has been shown (Gordis, Lilienfeld, and Rodriguez, 1969) to be the most significant factor in the epidemiology of rheumatic heart disease. The fact that the electrocardiograms of 11 children with non-ejection clicks or late systolic murmurs showed abnormalities described in the specific billowing mitral leaflet syndrome suggests that some of the Soweto children have this syndrome. However, the presence of a normal electrocardiogram in the remaining 147 children does not exclude the possibility of the billowing mitral leaflet syndrome and the aetiology still must remain in doubt. It is noteworthy that some workers (Steinfeld et al., 1974; Barlow and Pocock, 1975) have not observed an abnormal electrocardiogram, such as is seen in the billowing mitral leaflet syndrome, in patients with a non-ejection click or late systolic murmur resulting from rheumatic heart disease.

Against the background of low socioeconomic status in Soweto and the high prevalence of rheumatic heart disease, it is possible that an unknown and probably large number of children with late systolic murmurs or non-ejection systolic clicks have mild rheumatic heart disease. Further elucidation of the problem is necessary. The only practicable method would be to follow up such children who are not on specific prophylaxis against rheumatic fever to observe the natural history and, where possible, to examine the members of their families to detect rheumatic heart disease or a familial incidence of the billowing mitral leaflet syndrome. Studies of the prevalence of these features in other population groups in which rheumatic heart disease is less prevalent would be contributory.

\section{References}

Allen, H., Harris, A., and Leatham, A. (1974). Significance and prognosis of an isolated late systolic murmur: a 9- to 22-year follow-up. British Heart fournal, 36, 525.

Barlow, J. B. (1965). Conjoint clinic on the clinical significance of late systolic murmurs and non-ejection systolic clicks. fournal of Chronic Diseases, 18, 665.

Barlow, J. B., Bosman, C. K., Pocock, W. A., and Marchand, P. (1968). Late systolic murmurs and non-ejection ('midlate') systolic clicks. An analysis of 90 patients. British Heart fournal, 30, 203.

Barlow, J. B., and Pocock, W. A. (1975). The problem of nonejection systolic clicks and associated mitral systolic 
murmurs: emphasis on the billowing mitral leaflet syndrome. American Heart fournal, 90, 636.

Bon Tempo, C. P., Ronan, J. A., De Leon, A. C., and Twigg, H. L. (1975). Radiographic appearance of the thorax in systolic click-late systolic murmur syndrome. American Fournal of Cardiology, 36, 27.

Chesler, E., Levin, S., Du Plessis, L., Freiman, I., Rogers, M., and Joffe, N. (1966). The pattern of rheumatic heart disease in the urbanized Bantu of Johannesburg. South African Medical fournal, 40, 899.

Cobbs, B. W. (1974). Rheumatic heart disease and other acquired valvular disease. The Heart: Arteries and Veins, p. 882. Ed. by J. W. Hurst, R. B. Logus, R. C. Schlant, and N. K. Wenger. McGraw-Hill, New York.

Cochran, W. G. (1963). Sampling Techniques, 2nd ed. Wiley, New York.

Criley, J. M., Lewis, K. B., Humphries, J. O., and Ross, R. S. (1966). Prolapse of the mitral valve: clinical and cineangiocardiographic findings. British Heart fournal, 28, 488.

Du Plessis, L. A., and Chesler, E. (1969). Surgery for severe rheumatic mitral regurgitation in children. Fournal of Thoracic and Cardiovascular Surgery, 58, 730.

Epstein, E. J., and Coulshed, N. (1973). Phonocardiogram and apex cardiogram in systolic click-late systolic murmur syndrome. British Heart fournal, 35, 260.

Fontana, M. E., Pence, H. L., Leighton, R. F., and Wooley, C. F. (1970). The varying clinical spectrum of the systolic click-late systolic murmur syndrome. A postural auscultatory phenomenon. Circulation, 41, 807.

Gordis, L., Lilienfeld, A., and Rodriguez, R. (1969). Studies in the epidemiology and preventability of rheumatic fever II-Socio-economic factors and the incidence of acute attacks. Fournal of Chronic Diseases, 21, 655.

Grossman, H., Fleming, R. J., Engle, M. A., Levin, A. H., and Ehlers, K. H. (1968). Angiocardiography in the apical systolic click syndrome. Left ventricular abnormality, mitral insufficiency, late systolic murmur and inversion of $T$ waves. Radiology, 91, 898.

Gulotta, S. J., Gulco, L., Padamanabhan, V., and Miller, S. (1974). The syndrome of systolic click, murmur, and mitral valve prolapse-a cardiomyopathy? Circulation, 49, 717.

Hancock, E. W., and Cohn, K. (1966). The syndrome associated with midsystolic click and late systolic murmur. American fournal of Medicine, 41, 183.

Jeresaty, R. M. (1973). Mitral valve prolapse-click syndrome. Progress in Cardiovascular Diseases, 15, 623.

Kalbian, V. V. (1973). The mechanism of mitral regurgitation in carditis of acute rheumatic fever. American Heart fournal, 85, 139.

Kanarek, K. S., Bloom, K. R., Lakier, J. B., Pocock, W. A., and Barlow, J. B. (1973). Clinical aspects of submitral left ventricular aneurysms. South African Medical fournal, 47, 1225.

Lachman, A. S., Bramwell-Jones, D. M., Lakier, J. B., Pocock, W. A., and Barlow, J. B. (1975). Infective endocarditis in the billowing mitral leaflet syndrome. British Heart Fournal, 37, 326.

Leon, D. F., Leonard, J. J., Kroetz, F. W., Page, W. L., Shaver, J. A., and Lancaster, J. F. (1966). Late systolic murmurs, clicks, and whoops arising from the mitral valve. American Heart fournal, 72, 325.

Linhart, J. W., and Taylor, W. J. (1966). The late apical systolic murmur. Clinical, hemodynamic and angiographic observations. American fournal of Cardiology, 18, 164.
McLaren, M. J. (1969). Cryptogenic cardiomyopathy in the Bantu of Southern Africa. Leech, 39, 24.

McLaren, M. J., Hawkins, D. M., Koornhof, H. J., Bloom, K. R., Bramwell-Jones, D. M., Cohen, E., Gale, G. E., Kanarek, K., Lachman, A. S., Lakier, J. B., Pocock, W. A., and Barlow, J. B. (1975). Epidemiology of rheumatic heart disease in B'ack schoolchildren of Soweto, Johannesburg. British Medical fournal, 3, 474.

Pocock, W. A., and Barlow, J. B. (1970). Postexercise arrhythmias in the billowing posterior mitral leaflet syndrome. American Heart fournal, 80, 740.

Pocock, W. A., and Barlow, J. B. (1971). Etiology and electrocardiographic features of the billowing posterior mitral leaflet syndrome. American fournal of Medicine, 51, 731.

Popp, R. L., Brown, O. R., Silverman, J. F., and Harrison, D. C. (1974). Echocardiographic abnormalities in the mitral valve prolapse syndrome. Circulation, 49, 428.

Read, R. C., Thal, A. P., and Wendt, V. E. (1965). Symptomatic valvular myxomatous transformation (the floppy valve syndrome). A possible forme fruste of the Marfan syndrome. Circulation, 32, 897.

Reid, J. V. O. (1961). Mid-systolic clicks. South African Medical fournal, 35, 353.

Rizzon, P., Biasco, G., Brindicci, G., and Mauro, F. (1973). Familial syndrome of midsystolic click and late systolic murmur. British Heart fournal, 35, 245.

Schwartz, M. B., Schamroth, L., and Seftel, H. C. (1958). The pattern of heart disease in the urbanized (Johannesburg) African. Medical Proceedings, 4, 275.

Seftel, H. C., Kew, M. C., and Bersohn, I. (1970). Myocardial infarction in Johannesburg Bantu. South African Medical fournal, 44, 8.

Shappell, S. D., Marshall, C. E., Brown, R. E., and Bruce, T. A. (1973). Sudden death and the familial occurrence of mid-systolic click, late systolic murmur syndrome. Circulation, 48, 1128.

Shell, W. E., Walton, J. A., Clifford, M. E., and Willis, P. W. (1969). The familial occurrence of the syndrome of midlate systolic click and late systolic murmur. Circulation, $39,327$.

Steinfeld, L., Yeh, H.-C., Bloom, M., and Dimich, I. (1974). The variability of mitral valve prolapse (MVP) in rheumatic heart disease (abstract). Circulation, 49 and 50, Suppl. 3, 208.

Still, G. F. (1915). Common Disorders and Diseases of Childhood, 3rd ed. H. Frowde, London.

Tavel, M. E., Campbell, R. W., and Zimmer, J. F. (1965). Late systolic murmurs and mitral regurgitation. American Fournal of Cardiology, 15, 719.

Tucker, R. B. K., Zion, M. M., Pocock, W. A., and Barlow, J. B. (1975). Auscultatory features of hypertrophic obstructive cardiomyopathy. A study of 90 patients. South African Medical fournal, 49, 179.

Willems, J., Roelandt, J., De Geest, H., Kesteloot, H., and Joossens, J. V. (1969). Late systolic murmurs and systolic non-ejection clicks. Acta Cardiologica, 24, 456.

Wilson, M. G. (1962). The life history of systolic murmurs in rheumatic heart disease. Progress in Cardiovascular Diseases, 5, 145.

Requests for reprints to Professor J. B. Barlow, Cardiac Unit, Department of Medicine, Witwatersrand University, Johannesburg, Republic of South Africa. 